\title{
UMA LEITURA DA GREVE DA FORÇA PÚBLICA DE SÃO PAULO (13 E 14 DE JANEIRO DE 1961) - ENTRE O CORPORATIVISMO E A POLÍTICA ${ }^{1}$
}

\author{
The force public strike in São Paulo (13 and 14 \\ january 1961) - between corporatism and politics
}

\author{
André Rosemberg ${ }^{*}$
}

\begin{abstract}
RESUMO
Em janeiro de 1961, os policiais da Força Pública de São Paulo entraram em greve durante dois dias. $\mathrm{O}$ ato dramático, em que foi tomado o quartel do Corpo de Bombeiros no centro da capital, e paralisado o serviço em outras companhias, reivindicava aumento salarial e paridade de vencimentos com o quadro do funcionalismo civil. Ainda que inicialmente as demandas dos grevistas fossem de ordem corporativa e profissional, havia um forte aspecto político na paralisação. $\mathrm{O}$ evento paredista não pode ser tomado como um ato isolado: ele está plenamente embebido no contexto político-social dos anos que precederam o golpe de 1964.
\end{abstract}

Palavras-chave: Força Pública, greve, corporativismo

\begin{abstract}
In January of 1961, Força Pública (police corps) de São Paulo went on a two-day strike. This dramatic event resulted in the occupation of the Fire Corps Headquarters and the paralysis of activities in other companies. The policemen demanded a pay rise and wage parity with that of civil servants. Although the initial

1 Uma versão deste artigo foi publicada originalmente em Vingtième siècle - revue

* Pesquisador de pós-doutorado no Programa de Pós-graduação em História Social, PUC/SP. E-mail para contat: andrerosemberg@usp.br
\end{abstract} d'histoire, n. 128, outubro-dezembro de 2015. 
demands of the strikers were of a corporative and professional nature, there was a strong political undercurrent in the shutdown. The strike cannot be taken solely as an isolated act: it is fully immersed in the socio-political context of the years preceding the 1964.

Keywords: police corps, strike, corporatism

"Alastrou-se a várias unidades da FP a greve deflagrada ontem pelos bombeiros de São Paulo".

As letras garrafais do dia 14 de janeiro de 1961 davam o ar de drama para a notícia que estampava o jornal $A$ Folha de $S$. Paulo. $\mathrm{O}$ texto carregado de tensão informava sobre a greve no Corpo de Bombeiros, "irrompida pouco depois das $8 \mathrm{~h} 30$ da manhã" de ontem, em "sinal de protesto contra o nível de seus soldos". 2

Ainda segundo o jornal, o motivo que teria desengatilhado a paralisação dos serviços dos bombeiros e, em seguida, se alastrando para outras unidades do serviço prestado pela Força Pública (Radio Patrulha, o $2^{\circ}$ Batalhão, o $10^{\circ}$ Batalhão, o Regimento Nove de Julho e unidades do interior, como em Santo André), foi a negativa da Assembleia Legislativa do Estado de São Paulo em conceder a paridade salarial dos milicianos com seus homólogos da Polícia Civil (PC) e com o resto do funcionalismo público, que receberam, no mesmo ato, $40 \%$ de abono salarial.

O núcleo da greve durou dois dias -13 e 14 de janeiro envolveu mais de mil policiais ${ }^{3}$, levando ao indiciamento de 513 policiais, entre capitães (a mais alta patente entre os envolvidos), tenentes, subtenentes (aspirantes a oficial), sargentos, cabos e soldados. $\mathrm{O}$ inquérito foi conduzido por um delegado do Departamento de Ordem Política e Social (DOPS).

A greve da Força Pública está enquadrada num contexto crítico da história recente brasileira. Dá-se num momento paradoxal, em que, ao mesmo tempo que as instituições democráticas funcionavam com viço inédito, pulsava no seio de uma parcela importante da elite política e militar um afã reacionário que pretendia 
impor um projeto político conservador, ainda que às expensas desses mesmos princípios democráticos que vigoravam desde 1946. Sem nos enveredarmos por um prisma teleológico a posteriori, a parede dos policiais em 1961 aponta tanto para a ampliação da arena pública aos debates sobre os rumos a serem seguidos pela nação, como um sinal da confrontação ideológica que compõe as circunstâncias do golpe civil-militar que levou à queda do governo João Goulart três anos mais tarde. ${ }^{4}$

\section{I-A greve no contexto político}

O evento grevista de 1961, apesar de se apresentar como objeto pleno de interesse autônomo, está atrelado a um contexto bem mais amplo, que envolve o período politicamente turbulento a marcar o final do primeiro governo de Getúlio Vargas (1945) até o Golpe de 1964. Esse é um período denominado de "experiência democrática". 5 No curso desse interregno, ainda que com muitas instabilidades e laivos de arbítrio, as instituições políticas formais (partidos e parlamento) funcionaram com um mínimo de credibilidade, levando a uma participação inédita da população no mercado político, tanto se fazendo presente nos pleitos eleitorais, como por meio de outros canais que se abriram com o fim da Ditadura do Estado Novo (19371945), a exemplo dos sindicatos, das associações operárias, das ligas campesinas, etc. ${ }^{6}$

4 As múltiplas interpretações que analisam a genealogia, as causas e o desenlace do golpe fogem do escopo deste artigo. Para um apanhado geral e revisão bibliográfíca recente, ver Carlos Fico, Além do golpe - versóes e controvérsias sobre 1964 e a Ditadura Militar, Rio de Janeiro, Record, 2014.

5 Ver Jorge Ferreira, “A democratização de 1945 e o movimento queremista”, in: Jorge Ferreira e Lucilia de Almeida Neves Delgado (org), O Brasil Republicano - o tempo da experiência democrática, da democratização de 1945 ao golpe civil-militar de 1964 - vol. 3, Rio de Janeiro, Editora Civilização Brasileira, 2013, pp. 13-46. Ver também, do mesmo autor, Apresentação, in: Tempo, vol.14, n. 28, junho, 2010, "dossiê 1946-1964: a experiência democrática no Brasil", pp. 818.

6 Lucilia Neves de A. Delgado, "Trabalhismo, nacionalismo e desenvolvimentismo: um projeto para o Brasil (1945-1964)", in: Jorge Ferreira (org), O populismo e sua história: debate e crítica, Rio de Janeiro, Editora Civilização Brasileira, pp. 167-204. 
Nos anos 1940-1950 cresceu exponencialmente a reivindicação direta dos trabalhadores, que muitas vezes se organizavam alheios ao aparelho cooptador oficial, localizado no Ministério do Trabalho ou no sistema de sindicatos únicos. Foi comum a realização de greves interssindicais que envolviam 300 mil, 400 mil ou mesmo 700 mil trabalhadores, arrochados por um contexto de inflação galopante e de carestia de produtos básicos. ${ }^{7}$

A greve dos policiais da Força Pública em 1961 insere-se nesse contexto mais amplo, de descontentamento e reivindicação dos trabalhadores por uma participação mais ativa na divisão das riquezas geradas pelo processo de modernização do parque industrial brasileiro e na condução em torno das políticas que geriam as relações de trabalho. ${ }^{8} \mathrm{O}$ insueto do movimento policial é que ele se trata de uma espécie de inversão inopinada do lugar social que deviam ocupar na organização da vida social: a polícia, segundo o discurso dominante, deve se desincumbir, nas grandes linhas, da manutenção da ordem e do controle social. A irrupção de um movimento paredista, com piquetes e a reunião de centenas de milhares de pessoas, mesmo que habilitado por uma legislação democrática, deve ser acompanhada de perto pelos policiais, quando não reprimida, violentamente, devido a seu potencial desestabilizador; máxime se considerarmos a fragilidade institucional da democracia brasileira do período.

A greve da polícia se articula às dinâmicas políticas do período e demonstram as complexidades das alianças político-sociais, as ambiguidades inerentes às instituições $\mathrm{e}$ as possibilidades divergentes que configuravam a paleta de oportunidades no pré-1964. O movimento paredista é uma expressão desse estado de coisas, que, enxergado por outro prisma, deixou extravazar o aspecto meramente

7 Antonio Luigi Negro e Fernando Teixeira da Silva, "Trabalhadores, sindicatos e política (1945-1964), in: Jorge Ferreira e Lucilia de Almeida Neves Delgado (org), O Brasil Republicano - o tempo da experiência democrática, da democratização de 1945 ao golpe civilmilitar de 1964 - vol. 3, Rio de Janeiro, Editora Civilização Brasileira, 2013, pp. 47-96.

8 Ângela de Castro Gomes, A invenção do trabalhismo, Rio de Janeiro, Editora FGV, 2005. 
político da greve, emprestando à insatisfação classista uma dimensão mais holística do papel social cumprido pela polícia e pelo policial. ${ }^{9}$

A greve dá mostras da viabilidade de que os policiais organizassem coalizões e convergissem interesses profissionais e corporativos que passavam ao largo das prescrições oficiais e hierárquicas. Nesse ponto, o policial deixa de ser visto como um autômato nas mãos de elites econômicas e do governo e passa a ser encarado como um ator essencial na ampla arena de disputas. Seu lugar de mero repressor dos excessos trabalhistas (repressão a greves, por exemplo) é mitigado quando se tem acesso ao repertório de demandas dos policiais e de suas articulações com grupos de trabalhadores que compartilhavam experiências similares.

****

Como fonte para realizar este texto, utilizei basicamente a documentação produzida pelo DOPS, que reúne além de recortes de jornal, fotografias, cópias de panfletos e relatórios secretos produzidos por agentes. O relatório final do inquérito (cuja totalidade não localizei) também está disponível no material produzido pelo DOPS. A greve da polícia não chamou muito a atenção da historiografia da polícia. Thaís Battibugli é a única a abordar o tema, ainda que não se aprofunde nos meandros do episódio. ${ }^{10}$ Neste artigo, faço uma crônica mais substancial do que foi a greve da Força Pública, de acordo com a interpretação dos membros do DOPS, fazendo ressaltar o clima de rivalidade que contrapunha as instituições. Ao mesmo tempo, pretendo realçar o temor que transparece no discurso oficial de que a milícia estadual, pelo menos entre os escalões subalternos, cedesse à ideologia "comunista", num ambiente em que a polarização direita-esquerda pautou o debate político.

9 Para uma crítica dessa posição na historiografia brasileira, ver André Rosemberg, "A greve pelas oito horas em Santos (1908): em busca do inimigo imaginário", História \& Perspectivas, 49, jul-dez 2012.

10 Thais Battibugli, op. cit., pp. 138-155. 
A importância deste artigo deve-se, em primeiro lugar, ao fato de que a historiografia brasileira sobre a polícia relega o dito intervalo democrático, priorizando o estudo das polícias durante a Primeira República ou no governo Vargas, principalmente quando assume caráter ditatorial; em segundo lugar, o olhar especializado, principalmente aquele que se debruça sobre a Era Vargas, prefere ressaltar as operações do DOPS, que joga o papel de polícia política. Uma história sociocultural da polícia ostensiva (a Força Pública, no caso) é relegada. ${ }^{11}$

\section{II - O espectro do comunismo ronda a Força Pública}

Com o fim da Segunda Guerra Mundial, na partição do orbe entre as duas superpotências, os Estados Unidos se esforçaram em colocar sob sua tutela direta os países da América Latina. Políticas como Brother Sam previam investimentos vultosos para o desenvolvimento de sociedades democráticas alinhadas com o livre mercado, principalmente com a assunção de John Kennedy do governo, em 1960. ${ }^{12}$ A despeito de uma aparente independência em relação à influência dos dois grandes blocos, a presença norteamericana no Brasil foi patente, mesmo antes do golpe de 1964, momento em que se flagrou a participação direta das agências de inteligência estadunidense no desenrolar do putsch.

Durante o período democrático, em áreas estratégicas, como a da Segurança Pública, a cooperação Brasil-EUA se mostrou bastante íntima. Houve trânsito fluente de agentes americanos no Brasil e a visita de policiais brasileiros aos EUA para intercâmbio de

11 Um balanço recente sobre a historiografia da polícia brasileira está disponível em Marcos Luiz Bretas e André Rosemberg, "A história da polícia no Brasil: balanço e perspectivas", Topoi, 14(26), jan./jul., 2013.

12 Isabelle Vagnoux, «Um glacis du monde occidental - Washington et les régimes militaires sud-américains (1964-1989): des alliances encombrantes», Vingtième Siècle. Revue d'Histoire, 105, jan.-mars, 2010 ; Carlos Fico, O Grande Irmão: da operação Brother Sam aos anos de Chumbo - o governo dos Estados Unidos e a Ditadura Militar brasileira, São Paulo, Civilização Brasileira, 2008. 
expertise. ${ }^{13}$ Em plena Guerra Fria, o inimigo da ordem estava decido: o comunismo e a subversão. Os rótulos eram propositadamente arbitrários. Há um movimento anticomunista bastante fundado na história brasileira e que se renova a partir da década de 1950. O "perigo vermelho" passa a ser identificado com bandeiras esquerdistas para além de intelectuais e ativistas sindicais, tradicionalmente relacionados ao ideário comunista. $\mathrm{O}$ "combate" à ameaça marxista-leninista amplia o rol dos inimigos a serem debelados e agrega ao campo "democrático" (o qualificativo, vazio de sentido concreto, que se torna o contraponto do comunismo) uma plêiade de simpatizantes pertencentes a amplos estratos sociais, de instituições religiosas a associações civis e sindicatos patronais. ${ }^{14}$

Dentro desses limites pouco precisos de um lado a outro da arena ideológica, como se definia um comunista? O PCB estava na ilegalidade desde 1947 e o qualificativo era resiliente o bastante para tachar os inimigos políticos e aqueles que reivindicavam mudança na estrutura social do país: uma distribuição mais equânime de renda, reforma agrária, reforço dos direitos trabalhistas, independência sindical, ampliação da franquia eleitoral. Comunista, portanto, era a carapuça que identificava, além dos que professavam sua fé em Marx e Lênin a partir de canais representativos (o partido, as associações, os sindicatos), os potenciais detratores da ordem e da tranquilidade pública, aqueles que ameaçavam a estrutura social do país, baseada na morigeração e na deferência às instituições. ${ }^{15} \mathrm{O}$ comunista era o inimigo a ser combatido; e o comunismo, o credo a ser banido. Tratava-se de verdadeira questão de Segurança Nacional, cuja lei, promulgada em 4 de abril de 1935, serviu de base, mais tarde para legitimar as exações extrajurídicas do governo militar (pós-1964) contra os "inimigos do regime".

13 Thaís Battibugli, op. cit., pp. 227-256 et Martha K. Huggins. Political policing. The United States and Latin America. Durham, Duke University Press, 1988.

14 Sobre a presença comunista no país e as políticas de prevenção, ver Rodrigo Patto Sá Motta, Em guarda contra o perigo vermelho, São Paulo, Perspectiva, 2002 e Marcos Napolitano, Rodrigo Czajka e Rodrigo Patto Sá Motta (orgs), Comunistas brasileiros - cultura politica $e$ produção cultural, Belo Horizonte, Editora UFMG, 2013.

15 A complacência na definição dos "comunistas" deve-se ao entendimento de Jacob Goerender. Combate nas trevas. São Paulo: Atica, 2001. 
Em nome da Lei de Segurança Nacional, da defesa das fronteiras - reais e simbólicas - brasileiras contra a ameaça do comunismo internacional, todo e qualquer meandro de contaminação era escrutinado pelos aparatos da polícia secreta, reunidos no DOPS, inclusive no seio mesmo da Força Pública, que, por sua vez, se politizava num período em que o debate político se acirrou na arena pública.

Em 07 de maio de 1957, um ofício confidencial enviado pelo chefe de gabinete do Conselho de Segurança Nacional ao diretor do DOPS sob a rubrica "Comunismo na Força Pública de São Paulo" anunciava que

Há indícios de que a infiltração comunista no seio da FP de São Paulo esteja se processando através da criação, por parte do Comandante Geral de um Centro que congregue soldados e cabos da corporação. A propaganda não tem atingido somente às praças, mas também a oficialidade, pois, de uma maneira geral, reina o descontentamento naquela força. ${ }^{16}$

Em paralelo, a Força Pública utilizava os serviços da polícia política para levantar informações sobre a vida pregressa dos potenciais recrutas. $\mathrm{O}$ passado ligado a atividades tidas como subversivas ou a "células comunistas" podia inviabilizar o ingresso do postulante na corporação.

Um ofício do Serviço Secreto do DOPS para o Capitão Chefe de Alistamento da FP, em 21 de setembro de 1954, informava que Walter Rodrigues, "conforme boletim informativo do Estado do Rio de Janeiro, datado de 31 de dezembro de 1952, figura (...) como um dos signatários de mensagem de felicitações enviada a Stalin". Já Oswaldo da Silva “(...) figura em n/arquivo como um dos excertos da documentação do DOPS reproduzidos neste texto têm a mesma origem arquivística. 
signatários de empregados da Prefeitura Municipal que protestaram contra o processo de Luiz Carlos Prestes (...); e outro, também com esse mesmo nome, como um dos signatários do manifesto de lançamento do $2^{\circ}$ Festival da Juventude Paulista, entidade filiada à Juventude Comunista". ${ }^{17}$

Temia-se o espectro do comunismo pelo poder suasório das premissas igualitárias num período de descontentamento popular com a situação inflacionária e de carestia pela qual atravessava o país. Localizado na escala social mais baixa, com remuneração equivalente a de trabalhadores sem qualificação, os praças da Força Pública compartilhavam, fora do quartel, das mesmas agruras que seus homólogos sem farda. Malgrado estarem submetidos a regime militar, de rígida disciplina e hierarquia, os policiais não se sentiam parte excluída de uma "classe trabalhadora" mais ampla.

\section{III - Os preâmbulos da greve}

O descontentamento no seio da corporação era flagrante. Pelo menos desde o início da década de 1950, os agentes do DOPS e a imprensa de São Paulo recolhiam queixas de policiais da Força Pública. Em inúmeros boletins da polícia política identificava-se a reunião de núcleos reivindicatórios, mais ou menos organizados. $\mathrm{O}$ clima democrático, vigente desde 1946, e a turbulência na política local levavam os policiais a serem disputados por grupos políticos antagônicos. A cooptação da Força Pública podia se revelar um trunfo importante no resultado das urnas. Daí, a conscientização do papel que desempenhavam no equilíbrio eleitoral emprestava à corporação, sobretudo a seus membros de baixa patente, com menos comprometimento com a cúpula da alta burocracia política, instrumentos para pleitear melhores condições de trabalho, benefícios 
profissionais e corporativos e concessões paternalistas das parcialidades políticas que se enfrentavam.

Das principais reivindicações que brotam em meados da década de 1950, podemos salientar o clamor por um aumento categórico dos vencimentos, capaz de acompanhar o processo inflacionário, a equiparação de status da Força Pública com a Polícia Civil e a substituição do Comandante Geral da corporação, Coronel Arrison de Souza Ferraz, considerado muito próximo ao Secretário de Segurança Pública. Subjacentes a essas solicitações, desvela-se um sentimento de inferioridade da Força Pública em relação à sua correspondente civil, que historicamente gozava de maior prestígio junto às autoridades políticas. ${ }^{18}$ Clamava-se que a subordinação da Força Pública se desse diretamente com o governador do estado, e não mais por intermédio do Secretário de Segurança Pública. O orgulho militar e os arroubos de autonomia institucional repulsavam a intervenção da vertente civil da polícia (delegados, subdelegados) na organização e nos afazeres da Força Pública.

Um quadro de tensão evidente revolvia o cotidiano da Força Pública, trazendo desconforto (para dizer o mínimo) ao DOPS e à cúpula política de São Paulo. Uma ameaça insurrecional estava na ordem do dia, pelo menos se nos fiarmos nos relatórios oficiais. E, como sempre, o fantasma do comunismo rondava os quartéis, desviando os soldados de base e os oficiais de menor patente do bom caminho disciplinar.

Um relatório produzido pelo DOPS em 1954 dava conta de seguidas insubordinações no seio da Força Pública, a exemplo de faltas às revistas e o não comparecimento ao expediente. Segundo o agente da polícia política, a insubordinação estava vinculada às más condições de trabalho, como o regime de turno de 24 horas de trabalho por 24 horas de descanso. Na conclusão do ofício, lia-se: "A maioria dos soldados está descontente".

Em 1959, a insatisfação da tropa chegara a um nível preocupante. A imprensa de São Paulo, da mais situacionista, ligada ao governo Carvalho Pinto, à mais oposicionista, vinculada a Paulo, ver André Rosemberg, op. cit., principalmente capítulo 1. 
Adhemar de Barros, seu ferrenho opositor, tratava do tema da Força Pública com grande apreensão. As reivindicações por benefícios profissionais e corporativos se consolidavam, ao mesmo tempo em que se acirrava a disputa política no estado de São Paulo e no plano federal. Cobiçados como cabos eleitorais, os policiais, organizados em clubes e grêmios, se dividiam no apoio partidário a um ou outro candidato, dando vazão ao agitado ambiente político da virada da década de 1950.

No esteio reivindicatório da tropa, a tecla de independência em relação à Secretaria de Segurança Pública volta a ser premida pela cúpula da instituição. Uma moção do comando da Força Pública foi publicada em vários jornais paulistas em junho de 1959. No texto, o repúdio à interferência civil no cotidiano da corporação remete ao passado da instituição, durante a Primeira República (1889-1930), quando à polícia militar eram concedidas grandes parcelas de autonomia.

Rumores acerca de uma grande reforma policial, que extinguiria as polícias militares estaduais em favor de guardas civis municipais, ou boatos que davam conta da remoção da tropa para o interior do estado também agitavam os policiais. Havia uma vontade explícita de se manifestar politicamente através dos canais de representação institucional forjados nos interstícios das amarras disciplinares da Força Pública. O clima quente do final dos anos 1950 se fazia sentir na pressão quase insurrecional dos tenentes, os oficiais de mais baixa patente no quadro da polícia. Chamado de "tenentada" pelos órgãos da imprensa e pelos relatos do DOPS, esse "movimento" pressionava por melhorias nas condições gerais de trabalho e pleiteava a demissão do Comandante Geral, coronel Arrison de Souza Ferraz, considerado um capacho do Secretário de Segurança Pública. Como parte da pressão, os tenentes teriam invadido seu gabinete e bradado com rispidez. ${ }^{19}$ 


\section{IV - Crônica de uma greve}

O ano de 1960 começa igualmente tenso. No âmbito nacional, o final do governo JK acirra as disputa eleitoral entre Jânio Quadros e o Marechal Lott. ${ }^{20}$ Enquanto Jânio galvanizava, ainda que a contragosto, as forças conservadoras, ligadas à UDN; Lott representava as ambições progressistas, a continuação do nacionalismo-desenvolvimentista de Juscelino e a ambição de um governo mais à esquerda do gradiente político. Essa contenda transbordava para o plano estadual, onde os atores políticos se digladiavam por apoio (tanto mais que Jânio Quadros tinha sido governador paulista no quadriênio 1955-1959). ${ }^{21}$

O controle do aparato policial, principalmente da Força Pública, era essencial para o sucesso político. Embebida no tenso ambiente de época, a tropa jogava o jogo da politicagem. A percepção da instabilidade política, da presença de "agitadores de esquerda" e da pressão dos milicianos, principalmente os de baixa patente, com desafios explícitos à disciplina e à hierarquia militares, somados ao potencial disruptivo da tropa, ameaçava a estabilidade institucional. Não obstante as inclinações políticas dos policiais, cujos manifestos apoiavam ora um ora outro candidato, a macropolítica parece ter permanecido subjacente aos interesses mais pragmáticos da profissão e da carreira. Os diversos meetings e reuniões em grêmios e associações eram tidos como "cripto-comunistas" pelos agentes do DOPS. Recebiam também apoio explícito de outros grupos contestatórios como sindicatos e uniões estudantis.

O relatório de uma reunião de policiais da Força Pública em setembro de 1960 mostra bem o tom belicoso que envolvia a tropa. Durante o encontro - descreve o agente do DOPS

foi atacado o nome e a pessoa do senhor governador do Estado (...) Não há o espírito de disciplina nas fileiras e isso vem de ser proclamado pelos próprios oficiais (...)

20 Ver Thomas Skidmore, op. cit.

21 Thais Battibugli, op. cit., capítulo 4. 
Um tenente disse? "Já não posso mais exigir disciplina dos meus soldados porque também eu não sou disciplinado perante os meus superiores hierárquicos" (...) A reunião marcada para quarta-feira será decisiva: ou o governo cede ou a FP não mais acatará as decisões [ilegível]. ${ }^{22}$

Em mais um relatório, agentes do DOPS aventam a existência de um espírito de cisão no meio da tropa, entre "aqueles que acham que tudo deve ser conseguido dentro de um regime de disciplina militar; e outra que (influenciada por um espírito político imoderado) deixa-se levar por gestos e atitudes não tão condizentes com a disciplina da corporação". 23

Se há um estopim que desencadeia os eventos, no caso da greve da Força Pública, esse acontecimento foi a negativa da Assembleia Legislativa em conceder compensação salarial aos soldados equivalente à dos outros funcionários públicos, inclusive os policiais civis. A votação causou profunda frustração na tropa. Relatos da imprensa e do DOPS dão conta de cenas de desespero entre os policiais no momento em que se divulga o resultado da votação. Conforme escreveu o delegado responsável pelo inquérito que investigou o movimento, “(...) um oficial desmaiou, outro deu forte soco na perua do Departamento de Ordem Política e Social estacionada nas imediações, soldados gritavam, choravam e eram atacados de crises nervosas, o que bem denota o estado psicológico de que estavam possuídos". ${ }^{24}$

O relatório final do inquérito dá conta - em linguagem pouco protocolar - da marcha dos eventos:

Assim é que, na manhã em que caiu a aspiração dos milicianos, os trabalhos mais reclamados pela coletividade começaram a entrar em colapso. A

22 AESP, DOPS 50-D-18, pasta 8. Ofício do dia 19/09/1960.

23 AESP, DOPS 50-D-18, pasta 8. Ofício do dia 19/07/1960.

24 Relatório final do Delegado João Rannali no Inquérito que apurou a greve de 13, 14 de janeiro de 1961, em 03 de maio de 1961. 
interrupção de serviços teve início no Corpo de Bombeiros e ganhou, num repente, o Batalhão de Rádio Patrulha e o de Policiamento - que destaca para a Zona Leste da cidade [de São Paulo]. O município periférico de Santo André conheceu, igualmente, os efeitos da greve. No território que cabia à Milícia policiar, a ausência dos mantenedores da ordem foi quase que total. A Rádio Patrulha ficou inativa $\left(12^{\circ}\right.$ Batalhão $){ }^{25}$

$\mathrm{O}$ fato de a greve ter se iniciado entre os bombeiros intrigou as autoridades. Ainda que o Corpo de Bombeiros fizesse parte da Força Pública, a missão enobrecida - sem desempenhar nenhuma função repressiva - de que se desincumbiam os colocava numa posição mais vantajosa em relação ao público, que os tinha em boa conta. Na manhã do dia 13, entretanto, o quartel central da corporação, na Praça Clóvis de Beviláqua, no centro da capital, fícou tomada pelos paredistas. Num ato de grande simbologia, o tenente Celestino Henrique Fernandes determinou a um subordinado que içasse a escada magirus em frente ao quartel, ornando-a, em seu topo, com uma bandeira preta, em sinal de "luto pelas mortes das [nossas] reivindicações". ${ }^{26}$

Na sequência, a telegrafia do Corpo de Bombeiros transmitiu a ordem de greve para os destacamentos de todas as outras zonas da capital. Os comandantes de prontidão começaram a enviar os caminhões e o pessoal rumo ao quartel principal, centro da mobilização. Uma vez no quartel, os carros foram estacionados. Ainda segundo o delegado do DOPS, “(...) sempre que uma ameaça pairava sobre os milicianos, tenentes e aspirantes refreavam os impulsos dos soldados mais exaltados, disciplinavam-nos e chamavam-nos à realidade para que a paralisação de serviços não descambasse para a masorca". ${ }^{27}$ Para evitar confrontos mais sérios, os milicianos entregaram as armas, que foram recolhidas aos depósitos de cada unidade. 
Ainda no dia 13, quando a situação no quartel parecia contornada, com os cabeças do movimento votando pela retomada dos trabalhos, de inopino, chegaram oficiais (capitão Sidney Gimenez Palácios, tenentes Raul da Luz, Jatyr de Souza e Paulo Tenório da Rocha Marques) de outras unidades da Força Pública, anunciando a adesão ao movimento, o que inviabilizava o acordo de trégua. Um novo escrutínio foi realizado e greve teve continuidade, com o apoio maciço da tropa.

$\mathrm{Na}$ manhã do dia 14, as tropas do Exército cercaram o quartel. Um novo comandante geral da Força Pública foi empossado o coronel do Exército Caetano Figueiredo Lopes - com apoio do Ministério da Guerra. Entretanto, os soldados não cederam à autoridade e desobedeceram as ordens de "a postos" emanada pelo novo comandante. Tropas do Exército, mobilizadas para conter os possíveis desatinos dos bombeiros, foram estacionadas nas cercanias da caserna, emprestando um caráter marcial ao centro da cidade.

Outros acontecimentos dramáticos se seguiram quando soldados cercaram o coronel Caetano, novo comandante geral, retorquindo as suas palavras de alento e de estímulo à obediência e à disciplina. Entrementes, o comando da parede, driblando as ordens do Exército, em vez de fazer retornar os veículos às zonas de origem, retomando a normalidade, desviou-os rumo ao Palácio do Governo, nos Campos Elíseos, com vistas a confrontar diretamente o governador. Alguns soldados foram destacados para a garagem do Palácio a fim de evitar a fuga da autoridade.

Providencialmente - segue o relatório do inquérito -, o Exército Nacional, pelas tropas sediadas em São Paulo, estava alerta. Os generais Costa e Silva e Altair Franco Ferreira logo se faziam presentes e o primeiro, em tom enérgico e ameaçador, deu dois minutos de prazo para que os milicianos se retirassem porque, caso contrário, seriam "varridos à bala" por contingentes seus que estavam a caminho daquele local. Finalmente os oficiais revoltosos foram detidos pelo Coronel Caetano. ${ }^{28}$

O cerco ao Palácio do Governo gerou apreensão nas autoridades políticas confinadas no local. Segundo relatos da 
imprensa, até o governador pegou em armas para defender-se de uma possível invasão.

A convocação grevista, iniciada no Corpo de Bombeiros, ecoou em outras divisões da Força Pública. O $12^{\circ}$ Batalhão Policial, responsável pela Rádio Patrulha, se declarou solidário à greve, "deixando - segundo os termos do inquérito - de manter em funcionamento os setores a seu cargo, paralisaram as atividades a que estavam adstritos". ${ }^{29}$

Também se mostrou solidário o Segundo Batalhão Policial, composto por quatro companhias (uma administrativa, na sede do batalhão; as outras localizam-se na Penha, Vila Matilde e São Miguel, bairros da Zona Leste de São Paulo). No dia 13, solicitações da população não foram atendidas; na sede da Vila Maria foi hasteada uma bandeira preta. Em todas as companhias, os milicianos começaram a abandonar seus postos. Em São Miguel Paulista, "verificaram-se as cenas de maior rebeldia e onde patenteado ficou que o ânimo da tropa era marchar para a total paralisação de atividades, não só em sinal de solidariedade à campanha de aumento de soldo, mas também como prova de estima pelos oficiais que haviam sido presos". ${ }^{30}$ Soldados foram enviados à casa de colegas que estivessem de férias ou de folga, a fim de engrossar o contingente.

No Regimento Nove de Julho - unidade destacada para intervir no Corpo de Bombeiros, antes da interferência das Forças Armadas - foram detidos quatro capitães, sete tenentes e cinco aspirantes que "deixaram de cumprir ordens de serviço dos seus superiores, negando-se a intervir no Corpo de Bombeiros com o escopo de pôr fim à interrupção de trabalhos iniciadas pelo seu pessoal". O coronel Paulo da Cruz Mariano foi ter com os insurretos que disseram que "embora não tivessem armas, fariam uso de machadinhas para repelir a intervenção na unidade". ${ }^{31}$

Não há informações precisas do número exato de aderentes ao movimento. Nem o inquérito nem a imprensa chegam a uma cifra

29 Idem.

$30 \mathrm{Idem}$.

31 Idem. 
precisa. Os jornais especulam que tenha havido entre 500 e mil prisões durante os dias 13 e 14. O inquérito de mais de 2500 folhas, terminado em três de maio de 1961, pela lavra do Delegado Especializado de Ordem Social, João Ranali, ouviu 280 milicianos e doze testemunhas. Dos 513 indiciados no inquérito disciplinar, 63 foram submetidos a inquéritos policiais e 57 sofreram processos criminais por delitos de várias espécies que vão desde o crime contra a pessoa até os praticados contra a propriedade.

\section{VI-Consequências e algumas considerações finais}

No dia 15 de janeiro, ainda que os ânimos estivessem estirados, o ímpeto grevista arrefeceu. A presença das tropas do Exército, o compromisso com algumas das reivindicações corporativas e a campanha de repressão contra os líderes da insurreição desmotivaram os grevistas. De acordo com os termos do inquérito, a responsabilidade maior da vaga indisciplinar recaiu nas costas da baixa oficialidade - os tenentes. Apenas oito capitães foram indiciados, e nenhum tenente-coronel ou coronel. Os detidos foram levados ao quartel de Sorocaba, no interior do estado, onde esperaram os julgamentos civis e militares.

Em que pese o fim da greve, a politização em torno do movimento teve sequência. Uma passeata das esposas e filhos dos policiais foi convocada para o dia 20 de janeiro. Segundo relatos do DOPS, teriam tomado parte da manifestação 1500 pessoas, dentre as quais, dez policiais fardados, além de estudantes e operários, solidários à causa dos policiais. Antonio Chamorro, célebre líder comunista, "o orador mais violento de todos (...) afirmou que a FP deixou de espancar os operários para se unir a eles em seu próprio socorro. Afirmou também que juntos (operários e soldados) irão conseguir o congelamento de preços e outras reivindicações de há muito pleiteadas em benefício do povo". Os cartazes carregados pelas mulheres dos policiais davam o tom social da passeata. Entre outros, 
liam-se palavras de ordem, como 'Queremos Pão', 'Carvalho Pinto coveiro da FP', 'Anistia e 40\%, ${ }^{32}$

Por parte do governo, havia temor de que os "comunistas" capitalizassem os despojos do movimento. Vários políticos, sindicatos e associações, considerados de esquerda, se solidarizaram com os policiais, como o Sindicato dos Metalúrgicos, a União Ferroviária da Estrada de Ferro Sorocabana, a União Estadual dos Estudantes, o líder Jofre Correia Netto, os deputados "comunistas" Luciano Lepera e Ivete Vargas.

De acordo com os relatos do DOPS, o Partido Comunista Brasileiro, embora clandestino, estava intimamente ligado à articulação do movimento. A proximidade dos representantes da esquerda dos líderes do movimento paredista era flagrante, segundo se depreende das inferências dos agentes da polícia política.

[o] movimento [é] nitidamente orientado e insuflado pelo PCB, ainda não foi erradicado. Longe disso. Os elementos de maior gabarito naquela Força policial prosseguem estabelecendo contatos com militares do Exército e com políticos visando alcançar, com brevidade, o objetivo que se traçaram (...). ${ }^{33}$

No temor mais explícito das autoridades políticas, o espectro do comunismo fornecia a "ideologia" política que consubstanciava as reivindicações profissionais e corporativas. Conforme se depreende de algumas análises de contemporâneos, naquele período de turbulência política, a Força Pública não mais se coadunaria com o governo de plantão, mas sim aos interesses supinos do "povo". Em caso de revolta ou insurreição, com potencial de alterar a ordem institucional, a polícia militarizada defenderia os ideais revolucionários. O jornal $O$ Estado de $S$. Paulo num editorial que comentava a greve recém-terminada, atesta, sem meias palavras, a intenção golpista dos policiais, que teriam sido utilizados como 
instrumentos políticos do PTB e PSD para evitar a posse de Jânio Quadros, visando a "derrubar a ordem social". Ainda segundo o jornal, a contenção imediata do governo evitou que o conflito se espraiasse e contaminasse o ambiente político. ${ }^{34}$

É difícil nos fiarmos na argúcia dessa assertiva, isto é, crer que a Força Pública, principalmente na base de sua pirâmide hierárquica, se arvorasse a princípios ideológicos tão arraigados e coerentes. O temor de que, ao menos em São Paulo, a corporação possuísse potencial bélico para forçar a subversão do regime também pairava entre as autoridades. Pelo menos no plano do discurso, esse era o diagnóstico que se extrai da coleção de ofícios produzidos pelos agentes do DOPS e da leitura, nos interstícios, da retórica de políticos conservadores. Pode ser que o alarme fosse exagerado, e que se inflasse a força conspiratória da Força Pública e dos "comunistas", a fim de que ao governo de São Paulo fossem concedidos benefícios por parte da União.

Fica patente que, num grau menor ou maior, a Força Pública paulista se politizava num contexto de acirramento de projetos antagônicos. A corporação mostrou-se capaz de maquinar uma greve cuja ilegalidade infringia aspectos civis e militares. Seus líderes e os adesistas desafiaram os estatutos da Lei de Segurança Nacional e o Regulamento Disciplinar, subvertendo as noções e hierarquia. De fato, é difícil estabelecer uma linha rígida entre reivindicações meramente profissionais e corporativas de questões políticas de maior fôlego, como a ampliação da cidadania política - o direito de votar e ser votado - para praças e inferiores, até então excluídos da franquia eleitoral. ${ }^{35}$ Talvez essa divisão seja indevida, e no bojo das disputas de um projeto político que opunha, grosso modo, os herdeiros da política trabalhista de Getúlio Vargas, adeptos à modernização nacionalista, e o grupo conservador, atrelado ao liberalismo excludente, a Força Pública de São Paulo tenha mesclado durante as

34 Jornal O Estado de S. Paulo, 18 de janeiro de 1961.

35 Em setembro de 1963, parte dos sargentos do Exército Nacional se revoltou, em Brasília, contra a decisão do Supremo Tribunal Federal, que os excluía da franquia eleitoral, dando início a uma insurreição armada, mas de curta duração. Sobre o assunto, ver Paulo Eduardo Castello Parucker, Praças em pé de guerra - o movimento político dos subalternos militares no Brasil (1961-1964) e a Revolta dos Sargentos de Brasília. São Paulo, Expressão Popular, 2009. 
jornadas de 13 e 14 de janeiro de 1961 - evento culminante das insatisfações acumuladas - a pragmática profissional às demandas políticas mais abstratas.

Do episódio, também fica patente a cizânia, igualmente histórica, entre as instituições policiais de São Paulo, e a ambição de independência que impulsionava a Força Pública. É improvável que houvesse uma filiação ideológica tão clara ao "comunismo" e aos grupos de esquerda, a ponto de se corroborar a adesão consciente da maioria da tropa, tanto que a corporação não se opôs ao movimento golpista de 1964. Ao contrário: os Boletins Diários do pós-golpe (nos dias 1 e 2 de abril) louvaram a deposição de João Goulart. Os poucos recalcitrantes foram, nos anos subsequentes, expurgados da corporação.

Pode-se dizer, finalmente, que no intervalo democrático de 1946 a 1964, a Força Pública participou ativamente, e com toda a ambiguidade comum às organizações, em geral, e às organizações policiais, em particular, do conturbado contexto político. A greve de 1961, e seus significados controversos e ambivalentes, são uma demonstração inconteste desse fenômeno.

RECEBIDO EM: 15/05/2016 APROVADO EM: 20/06/2016 